\title{
Outcomes related to immediate extubation after stage 1 Norwood palliation for hypoplastic left heart syndrome
}

\author{
Joby Varghese, MBBS, ${ }^{a}$ James M. Hammel, MD, ${ }^{\mathrm{b}}$ Ali N. Ibrahimiye, MD, ${ }^{\mathrm{b}}$ Rebecca Siecke, PA-C, \\ Karl Stessy Bisselou Moukagna, MS, ${ }^{c}$ and Shelby Kutty, MD, PhD, MHCM $^{\mathrm{d}}$
}

\section{ABSTRACT}

Objective: Immediate extubation may have outcome benefits when judiciously instituted after neonatal congenital cardiac surgery. We sought to evaluate the outcomes of immediate extubation specifically in neonates undergoing stage 1 Norwood palliation of hypoplastic left heart syndrome.

Methods: Consecutive neonates undergoing stage 1 Norwood (January 2010 to December 2016) for hypoplastic left heart syndrome were retrospectively studied. Immediate extubation was defined as successful extubation before termination of anesthetic care. Preoperative and intraoperative variables were compared between immediate extubation and nonimmediate extubation groups, and bivariate analyses and descriptive methods were used to express the association of outcome variables with immediate extubation. Data were expressed as number and percent for categoric variables, and median and interquartile range for continuous variables.

Results: Of 23 patients who underwent stage 1 palliation, 5 had immediate extubation $(22 \%)$. There were no differences in preoperative or intraoperative factors between patients who did and did not undergo immediate extubation. There were no deaths in the immediate extubation group. In the nonimmediate extubation group, 3 patients died before hospital discharge. One patient who had immediate extubation and 4 patients among those who did not have immediate extubation had to be reintubated in the 96 hours that followed extubation $(P=1)$. Intensive care unit length of stay was $8(3-17)$ and 8 (5-18) (days) for the immediate extubation group and nonimmediate extubation groups, respectively $(P=.71)$.

Conclusions: Immediate extubation strategy was safely accomplished in one-fifth of this cohort of hypoplastic left heart syndrome. A larger cohort may delineate the determinants of immediate extubation and its benefits in infants undergoing stage 1 single ventricle palliation. (J Thorac Cardiovasc Surg 2019;157:1591-8)

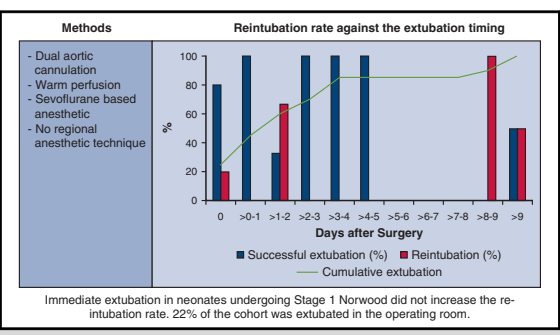

Feasibility of IE after Norwood stage 1 procedure.

Central Message

If judiciously instituted, IE strategy can be extended to neonates undergoing complex procedures including stage 1 Norwood palliation. A larger cohort study may shed more light on outcome benefits.

Perspective

IE after neonatal cardiac surgery may decrease ICU stay and expenses. We explored the feasibility of IE in neonates with HLHS who underwent a unique care pathway for Norwood stage 1 repair. A larger cohort may delineate the factors determining the possibility of IE and outcome benefits related to it.

See Commentaries on pages 1599 and 1601.
Hospital survival associated with surgical palliation for hypoplastic left heart syndrome (HLHS) has improved over time from $50 \%$ in the early 1980 s to approximately $90 \%$ in some centers. ${ }^{1,2}$ As the survival improved, the

\footnotetext{
From the a Department of Anesthesiology, Children's Hospital and Medical Center, Omaha, Neb; ${ }^{b}$ Division of Cardiovascular Surgery and ${ }^{\mathrm{c}}$ Department of Biostatistics, School of Public Health, and ${ }^{\mathrm{d}}$ Division of Pediatric Cardiology, University of Nebraska College of Medicine, Omaha, Neb.

Read at the 98th Annual Meeting of The American Association for Thoracic Surgery, San Diego, California, April 28-May 1, 2018.

Received for publication April 29, 2018; revisions received Oct 22, 2018; accepted for publication Oct 24, 2018; available ahead of print Jan 18, 2019.

Address for reprints: Joby Varghese, MBBS, Children's Hospital and Medical Center, Omaha, NE 68114 (E-mail: jvarghese@ childrensomaha.org). $0022-5223 / \$ 36.00$

Copyright (C) 2018 by The American Association for Thoracic Surgery https://doi.org/10.1016/j.jtcvs.2018.10.153
}

attention has shifted to longer-term outcomes, including neurodevelopment. Duration of mechanical ventilation and length of hospital stay after stage 1 Norwood palliation have been demonstrated to be independent predictors of Mental Development Index Score and Psychomotor Development Index Score. ${ }^{3}$ Duration of postoperative mechanical ventilation after stage 1 palliation is an independent predictor of extubation failure and length of hospital stay. ${ }^{4}$

Morbidity related to positive pressure ventilation in neonates after cardiac surgery is yet to be quantified. However, it has been demonstrated that excessive tidal strain in the alveoli of patients after cardiopulmonary bypass (CPB), acting synergistically with circulating endotoxins, can trigger an inflammatory response and lung injury. This could lead to additional cardiopulmonary 


$$
\begin{aligned}
& \text { Abbreviations and Acronyms } \\
& \text { CPB = cardiopulmonary bypass } \\
& \text { ECMO }=\text { extracorporeal membrane oxygenation } \\
& \text { HLHS }=\text { hypoplastic left heart syndrome } \\
& \text { ICU }=\text { intensive care unit } \\
& \text { IE }=\text { immediate extubation } \\
& \text { LOS }=\text { length of stay } \\
& \text { POD }=\text { postoperative day }
\end{aligned}
$$

morbidity even in those infants ventilated with lower tidal volumes. ${ }^{5}$

We and others have demonstrated the safety of immediate extubation (IE) in neonates undergoing open surgery. ${ }^{6,7}$ When neonates with a propensity to be extubated immediately after open surgeries were extubated in the operating room, there was a significant decrease in intensive care unit (ICU) length of stay (LOS) and ICU expenses. $^{6}$ At our institution, IE has therefore evolved into practice as a goal for all infants and children undergoing open surgery including neonates. This report constitutes our experience with IE after stage 1 Norwood palliation for HLHS.

\section{MATERIALS AND METHODS}

This was a single-center retrospective study. The institutional review board approved the protocol, and a requirement for informed consent was waived. Clinical records of all neonates who underwent stage 1 Norwood palliation for HLHS from January 1, 2010, to December 31, 2016, were reviewed. During the time of the study, no patient with an isolated HLHS was referred for comfort care or primary heart transplantation. Stage 1 Norwood was defined as an aortopulmonary connection and neoaortic arch construction resulting in univentricular physiology and pulmonary blood flow controlled with a nonvalved right ventricle to pulmonary artery (Sano) shunt per our institutional practice. IE was defined as successful extubation in the operating room. The time from the end of surgery to the time anesthesia and nursing personnel were relieved from the patient's care as documented in the anesthesia and nursing records, whichever was the longest, was obtained as the surrogate for operating room turnover time. Preoperative variables considered were age, weight, gender, gestational age, the need for mechanical ventilation, and the presence of genetic or chromosomal abnormalities. Intraoperative variables considered were CPB time, ischemic (aortic crossclamp) time, lowest temperature on $\mathrm{CPB}$, blood products (other than packed red blood cells) transfused intraoperatively, and the inotrope score at the termination of the anesthetic. Anatomic variables considered were (1) extent of mitral and aortic valve involvement and (2) gradient across the interatrial septum. Inotrope score was calculated by the following formula: inotrope score $=$ dosage $(\mu \mathrm{g} / \mathrm{kg} / \mathrm{min})$ of dopamine + epinephrine $100+$ milrinone. Outcome variables evaluated were reintubations, ICU LOS, and arrhythmias.

\section{Cardiopulmonary Bypass Technique}

The institutional CPB technique has been published. ${ }^{8}$ In brief, all patients received 2 doses of $10 \mathrm{mg} / \mathrm{kg}$ methylprednisolone sodium succinate each at 6 hours before surgery and on CPB initiation. Arterial pressure monitoring of both the right upper extremity and the lower body was established. The CPB circuit consisted of a Terumo FX05 oxygenator
(Terumo CV, Ann Arbor, Mich), 1/8"3/16" AV loop and 3/16" boot tubing with Terumo X coating. Myocardial preservation was accomplished using Del Nido cardioplegia at 1:4 blood to crystalloid ratio and the Terumo CapioxVR cardioplegia system. The prime consisted of Plasmalyte A (Baxter, Deerfield, Ill), 15 meq NaHCO3, $120 \mathrm{~mL}$ washed red blood cells, $75 \mathrm{~mL} 25 \%$ albumin, $25 \mathrm{mg} \mathrm{CaCl} 2$, and $100 \mathrm{mg} / \mathrm{kg}$ tranexamic acid. The prime was concentrated to a volume of $155 \mathrm{~mL}$ using the Terumo HCO5S hemofilter. The flow was targeted to $3.0 \mathrm{~L} / \mathrm{min} / \mathrm{m}^{2}$ and a perfusion pressure of $35 \mathrm{~mm} \mathrm{Hg}$ at mild hypothermia. Hematocrit was maintained at more than $25 \%$ with packed red blood cells given as needed. Zero balance ultrafiltration was used throughout the procedure with replacement fluid of 2/3 buffered normal saline (30 mEq NaHCO3/l added) and 1/3 0.45\% buffered saline. The CPB circuit incorporated two 8F, bulb-tipped RMI cannulae (Edwards Cardiovascular, Irvine, Calif) through a Y-connector and equal-sized tubing limbs.

\section{Surgical Technique}

Through a median sternotomy, the left pulmonary artery was ensnared to reduce pressure and risk of pulmonary hemorrhage. The innominate artery was dissected until its bifurcation, directly cannulated, and the cannula secured with the bevel facing the aorta so that coronary perfusion pressure was at least that measured at the wrist. An incision was made at the diaphragmatic pericardial reflection, to the right of the phrenic nerve, into the left pleural space, and continued rightward to the inferior vena cava. Sutures in the right and left ends of this flap were then elevated to each side to lift the heart. The aorta was dissected and cannulated directly. Venous cannulae were inserted. With the initiation of bypass, the ductus was divided. The proximal transverse aortic arch was snared shut, maintaining perfusion from the innominate cannula into the ascending aorta. The left carotid and subclavian arteries were snared, and a clamp was applied to the descending aorta. A partial clamp applied to the upper or lower arterial circuit is sometimes needed to balance pressures. The distal aortic reconstruction is completed. For cardioplegic arrest, the snare was tightened at the innominate artery, the transverse snare was removed, the incision in the arch was extended, and a cardioplegia cannula was inserted into the ascending aorta. All intracardiac work was performed, and then the proximal aortic patch was completed, incorporating a vent into the proximal suture line. The aorta was de-aired, and clamps and snares were removed. The descending aortic cannula was removed during weaning from bypass.

\section{Anesthetic Care}

All patients undergoing Norwood 1 with the Sano were considered as potential candidates for IE. In general, anesthetics were sevoflurane based, supplemented with intravenous agents. Every attempt was made to prevent pulmonary over-circulation during the prebypass period. Pancuronium, cisatracurium, or rocuronium was used as a relaxant. Regional techniques were not used.

A typical neonate undergoing open surgery received approximately $0.8 \mathrm{mg} / \mathrm{kg}$ of rocuronium on induction followed by an infusion at 5 to $7 \mu \mathrm{g} / \mathrm{kg} / \mathrm{min}$. Most patients received less than $10 \mu \mathrm{g} / \mathrm{kg}$ of fentanyl in the prebypass period. On sternal closure, rocuronium infusion was stopped, fentanyl (1-2 $\mu \mathrm{g} / \mathrm{kg} / \mathrm{h})$ and dexmedetomidine $(0.25-0.5 \mu \mathrm{g} / \mathrm{kg} / \mathrm{h})$ infusions were started, and intravenous acetaminophen $(10 \mathrm{mg} / \mathrm{kg}$ ) was given and muscle paralysis reversed. Postoperative hemodynamics was controlled with dopamine, epinephrine, milrinone, and sodium nitroprusside infusions connected to the central line before extubation, irrespective of their need at the time.

The decision to extubate was clinically driven and made by the anesthesiologist in consultation with the surgeon based on hemodynamic stability, hemostasis, and general lung function after sternotomy closure. After administration of the reversal agents, the respiratory effort was carefully monitored. Possible inaccuracy in registering low spontaneous tidal volumes and the significant resistance offered by endotracheal tube were 
TABLE 1. Association of preoperative and intraoperative variables and outcome measures with immediate extubation

\begin{tabular}{|c|c|c|c|c|}
\hline & Parameters & IE $(\mathbf{n}=\mathbf{5})$ & Non-IE $(n=18)$ & $P$ value \\
\hline \multirow[t]{5}{*}{ Preoperative factors } & Gestational age (wk) - median (IQR) & $39(38.1-39.4)$ & $39.1(38.1-39.6)$ & .91 \\
\hline & Age $(d)-$ median (IQR) & $15(4-16)$ & $5(4-7)$ & .27 \\
\hline & Weight (kg) - median (IQR) & $3.3(3.3-3.8)$ & $3.4(3.1-3.9)$ & .55 \\
\hline & Gender $($ male $)-\mathrm{n}(\%)$ & $4(24 \%)$ & $13(72 \%)$ & 1.00 \\
\hline & RIAS* $(>8 \mathrm{~mm} \mathrm{Hg})-\mathrm{n}(\%)$ & $2(40 \%)$ & $2(11.1 \%)$ & .19 \\
\hline \multirow[t]{5}{*}{ Intraoperative factors } & $\mathrm{CPB}(\min )$ & $105(105-138)$ & $103(95-129)$ & .58 \\
\hline & $\mathrm{XC}(\min )$ & $32(21-41)$ & $28(24-35)$ & .85 \\
\hline & $\mathrm{T} \min \left({ }^{\circ} \mathrm{C}\right)$ & $34(32-34)$ & $32.4(32.1-33.6)$ & .65 \\
\hline & Inotrope score & $5(5-10)$ & $5(5-9)$ & 1 \\
\hline & Platelets $(\mathrm{mL} / \mathrm{kg})$ & $12(0-12)$ & $16(0-28)$ & .56 \\
\hline \multirow[t]{4}{*}{ Outcomes } & Operating room turnover time $(\mathrm{min})$ median $(\mathrm{IQR})$ & $41(31-45)$ & $35(33-47)$ & .82 \\
\hline & Reintubation (96 h) & 1 & 4 & 1 \\
\hline & ICU LOS (d) & $8(3-17)$ & $8(5-18)$ & .71 \\
\hline & Post-ICU hospital stay (d) & $8(7-14)$ & $8(5-13)$ & .5 \\
\hline
\end{tabular}

$I E$, Immediate extubation; $I Q R$, interquartile range; $R I A S$, restrictive interatrial septum; $C P B$, cardiopulmonary bypass; $X C$, aortic crossclamp time; $T$ min, lowest temperature on bypass; $I C U$, intensive care unit; $L O S$, length of stay.

taken into account while considering spontaneous tidal volumes recorded by the anesthesia machine before extubation. All attempts were made to keep the neonates warm in the perioperative period.

\section{Statistical Methods}

Data were summarized as number and percent for categoric variables, and median and interquartile range for continuous variables. Univariate or bivariate analysis of preoperative, intraoperative, and anatomic variables was used to determine associations with IE. Data were analyzed by Fisher exact test and chi-square test for categoric variables and Mann-Whitney test for continuous variables. Regression analyses along with descriptive methods were also used to express associations. Commercially available statistical software (PC SAS version 9.4, SAS Institute, Inc, Cary, NC) was used.

\section{RESULTS}

Of the 23 patients who underwent stage 1 palliation for HLHS, 5 had IE $(22 \%$ of the cohort, $25 \%$ of all extubations). One patient had 3p11.2 deletion and another had 22q11 deletion. Hospital survival after stage 1 palliation of HLHS at our center was $87 \%$ during the study period. There were no deaths in the IE group. Three patients in the non-IE group who died before hospital discharge were excluded from ICU LOS and post-ICU LOS calculations. ICU LOS for the cohort was 8 (5-19) days, and postoperative hospital LOS was 19 (12-30) days. There were no differences in preoperative factors, intraoperative factors, or outcome measures between patients with and without IE (Table 1).

\section{Preoperative Factors}

Among the 3 patients who needed preoperative ventilator assistance on the day of the surgery, 1 also needed inotropic support. Two of the 3 patients needed to have open sternum postoperatively and 1 also needed extracorporeal membrane oxygen (ECMO) support.

Five patients in the cohort had pulmonary artery banding before stage 1 palliation. Three of these were performed in conjunction with interatrial septectomy/septostomy for the restrictive interatrial septum. Three patients had tachyarrhythmias preoperatively; 1 had atrial flutter, and 2 had atrial ectopic tachycardia. None of these patients had postoperative arrhythmias.

\section{Intraoperative Factors}

Intraoperative factors were not significantly different between patients with and without IE. Ten patients (43\%) in the entire cohort and 2 patients $(40 \%)$ in the IE group received no other blood products other than packed red blood cells. One patient received cryoprecipitate, and 1 patient received fresh-frozen plasma in addition to platelets; neither of them had IE. Three of the 4 patients who could not have the sternotomy closed at the end of stage 1 operation died during the hospitalization.

\section{Anatomic Factors}

These factors are shown in Tables 2 and 3. There were 4 patients who had restriction of the interatrial septum preoperatively (mean gradient $>8 \mathrm{~mm} \mathrm{Hg}$.). Two patients had interatrial septectomy, and 1 patient had interatrial stent placement along with pulmonary artery banding soon after birth, and all were extubated before stage 1 . Two of the 4 patients with atrial septal restriction had IE after Norwood stage 1 . Two patients had left ventricle to coronary artery fistulae and were mitral stenosis-aortic atresia variants of HLHS. One had the fistula diagnosed preoperatively, and the second fistula was diagnosed at autopsy (Table 3). 
TABLE 2. Anatomic features as they relate to extubation

\begin{tabular}{llr}
\hline \multicolumn{1}{c}{ Group } & \multicolumn{1}{c}{ Anatomy } & $\mathbf{n}$ \\
\hline IE $(\mathrm{n}=5)$ & HLHS, MS, AA & 1 \\
& HLHS, MA, AS, muscular VSD & 1 \\
& HLHS, MA, AA & 3 \\
& RIAS $>5 \mathrm{~mm} \mathrm{Hg}$ mean gradient & 3 \\
& RIAS $>8 \mathrm{~mm} \mathrm{Hg}$ mean gradient & 2 \\
\hline Non-IE $(\mathrm{n}=18)$ & HLHS, MS, AS & 2 \\
& HLHS, MS, AA & 2 \\
& HLHS, MA, AA & 14 \\
& RIAS $>5$ mm Hg mean gradient & 3 \\
& RIAS $>8$ mm Hg mean gradient & 2 \\
\hline
\end{tabular}

$I E$, Immediate extubation; $H L H S$, hypoplastic left heart syndrome; $M S$, mitral stenosis; $A A$, aortic atresia; $M A$, mitral atresia; $A S$, aortic stenosis; $V S D$, ventricular septal defect; RIAS, restrictive interatrial septum.

\section{Outcomes}

Features of patients in the IE group are summarized in Table 4.
Reintubations. One patient in the IE group (patient 13, Table 4, Central Image) and 4 patients in the non-IE group failed extubation in the 96 hours that followed. In the non-IE group, 2 extubation failures occurred among the 3 patients $(67 \%)$ who were extubated on postoperative day (POD) 2. One of them was reintubated within the first 45 minutes after extubation and was treated with steroids for edema of the vocal cords and re-extubated 42 hours later. The second patient was reintubated on the fourth day after extubation for respiratory insufficiency and was subsequently extubated on POD 9. Another patient had moderate tricuspid valve regurgitation after stage 1 and developed hyperlactatemia in the 72 hours that followed extubation on POD 8. This patient was treated with inotropes and re-extubated 5 days later. The fifth failed extubation occurred within 12 hours after the extubation on POD 52. This patient was subsequently extubated on POD 75. A graphical representation of the reintubation rate against the extubation timing is shown in Figure 1.

Arrhythmias. Four patients had supraventricular tachycardia in the immediate postoperative period

TABLE 3. Patients with restrictive interatrial septum (gradient $\geq 8 \mathrm{~mm} \mathbf{~ H g}$ )

\begin{tabular}{|c|c|c|c|c|c|c|c|c|c|c|c|c|}
\hline ID & GA & $\begin{array}{l}\text { Age } \\
\text { (d) }\end{array}$ & $\begin{array}{c}\text { Weight } \\
\text { (kg) }\end{array}$ & $\begin{array}{c}\text { Anatomic } \\
\text { diagnosis }\end{array}$ & $\begin{array}{l}\text { Preoperative } \\
\text { intervention }\end{array}$ & CPB & $\mathbf{X C}$ & $T \min$ & $\begin{array}{l}\text { Inotrope } \\
\text { score }\end{array}$ & Complications & Extubation & $\begin{array}{l}\text { ICU } \\
\text { stay }\end{array}$ \\
\hline 7 & $393 / 7$ & 16 & 3.1 & $\begin{array}{l}\text { HLHS, MA, AA, } \\
\text { right pulmonary } \\
\text { vein obstruction } \\
\text { and mean IAS } \\
\text { gradient } 10 \mathrm{~mm} \\
\mathrm{Hg} .\end{array}$ & $\begin{array}{l}\text { Right pulmonary } \\
\text { vein repair, } \\
\text { interatrial } \\
\text { septectomy and } \\
\text { pulmonary artery } \\
\text { banding } \\
\text { on DOL } 1\end{array}$ & 138 & 41 & 30.2 & 0 & $\begin{array}{l}\text { Laryngo-tracheo- } \\
\text { bronchomalacia } \\
\text { and } \\
\text { left vocal cord } \\
\text { palsy. } \\
\text { Reintubated on POD } \\
23 \text { for respiratory } \\
\text { distress and } \\
\text { subsequently } \\
\text { underwent } \\
\text { tracheostomy on } \\
\text { POD } 29 . \\
\text { Tracheostomy } \\
\text { was decannulated } \\
\text { at the age of } 97 \mathrm{~d}\end{array}$ & Immediate & 8 \\
\hline 12 & $394 / 7$ & 5 & 3.9 & $\begin{array}{l}\text { HLHS, MS, AS, } \\
\text { mean IAS } \\
\text { gradient 9-16 mm } \\
\mathrm{Hg}\end{array}$ & None & 98 & 24 & 32.3 & 0 & $\begin{array}{l}\text { Swallowing } \\
\text { incoordination }\end{array}$ & POD 1 & 18 \\
\hline 20 & 38 & 23 & 3.8 & $\begin{array}{l}\text { HLHS, MA, AA } \\
\text { with mean IAS } \\
\text { gradient } 11 \mathrm{~mm} \\
\text { Hg. }\end{array}$ & $\begin{array}{l}\text { Interatrial septal } \\
\text { stent } \\
\text { placement and } \\
\text { pulmonary artery } \\
\text { banding on } \\
\text { DOL } 0\end{array}$ & 148 & 38 & 34.5 & 5 & $\begin{array}{l}\text { Died at home after } \\
\text { discharge on } \\
\text { DOL } 57\end{array}$ & Immediate & 2 \\
\hline 23 & $386 / 7$ & 2 & 3.03 & $\begin{array}{l}\text { HLHS, MA, AA, } \\
\text { mean IAS } \\
\text { gradient } 9 \mathrm{~mm} \mathrm{Hg} \\
\text { mean }\end{array}$ & None & 104 & 27 & 32.5 & 5 & None & POD 1 & 3 \\
\hline
\end{tabular}

$\overline{G A}$, Gestational age; $C P B$, cardiopulmonary bypass; $X C$, aortic crossclamp time; $T$ min, lowest temperature on bypass; $I C U$, intensive care unit; $H L H S$, hypoplastic left heart syndrome; $M A$, mitral atresia; $A A$, aortic atresia; $I A S$, interatrial septum; $D O L$, day of life; $P O D$, postoperative day; $M S$, mitral stenosis; $A S$, aortic stenosis. 
TABLE 4. Brief description of patients who underwent immediate extubation

\begin{tabular}{|c|c|c|c|c|c|c|c|c|c|c|c|}
\hline Patient & GA & Age & Weight & Anatomic diagnosis & $\begin{array}{l}\text { Preoperative } \\
\text { intervention }\end{array}$ & CPB & $\mathrm{XC}$ & $\mathbf{T}$ min & $\begin{array}{c}\text { Inotrope } \\
\text { score }\end{array}$ & Complications & $\begin{array}{l}\text { ICU } \\
\text { stay }\end{array}$ \\
\hline 5 & $381 / 7$ & 16 & 3.3 & $\begin{array}{c}\text { HLHS, MA, AA, IAS } \\
\text { gradient } 5 \mathrm{~mm} \mathrm{Hg}\end{array}$ & $\begin{array}{l}\text { Interatrial septectomy } \\
\text { and PAB on DOL 0, } \\
\text { Extubated on DOL } 3\end{array}$ & 105 & 20 & 32 & 5 & $\begin{array}{l}\text { Left diaphragmatic palsy, } \\
\text { chylothorax, } \\
\text { enterococcal sepsis }\end{array}$ & 14 \\
\hline 7 & $393 / 7$ & 16 & 3.1 & $\begin{array}{l}\text { HLHS, MA, AA, IAS } \\
\text { gradient } 10 \mathrm{~mm} \mathrm{Hg} \text {, } \\
\text { right pulmonary vein } \\
\text { obstruction }\end{array}$ & $\begin{array}{l}\text { Right pulmonary vein } \\
\text { repair, interatrial } \\
\text { septectomy and } \\
\text { PAB on DOL 1, } \\
\text { Extubated on } \\
\text { DOL } 3\end{array}$ & 148 & 41 & 30.2 & 0 & $\begin{array}{l}\text { ICU readmission POD } 23 \\
\text { for aspiration, } \\
\text { tracheostomy on POD } \\
29 \text { for left vocal cord } \\
\text { palsy, } \\
\text { laryngotracheomalacia }\end{array}$ & 8 \\
\hline 13 & $412 / 7$ & 4 & 4.2 & HLHS, MS, AA & None & 105 & 43 & 34 & 10 & $\begin{array}{l}\text { Vomiting and aspiration } \\
\text { on POD } 1 \text { leading to } \\
\text { intubation and re- } \\
\text { extubation on POD } 2 \\
\text { Deglutition study showed } \\
\text { swallowing } \\
\text { abnormality that } \\
\text { improved with time }\end{array}$ & 20 \\
\hline 17 & 39 & 4 & 3.3 & $\begin{array}{l}\text { HLHS, MA, AS, VSD, } \\
\text { hypoplastic aortic arch }\end{array}$ & None & 82 & 21 & 34 & 10 & None & 3 \\
\hline 20 & 38 & 23 & 3.8 & $\begin{array}{r}\text { HLHS, MA, AA, IAS } \\
\text { gradient } 11 \mathrm{~mm} \mathrm{Hg}\end{array}$ & $\begin{array}{l}\text { Interatrial septal } \\
\text { stent and PAB on } \\
\text { DOL } 0 \text { and } \\
\text { extubated on } \\
\text { DOL } 7\end{array}$ & 148 & 32 & 34.5 & 5 & None & 2 \\
\hline
\end{tabular}

GA, Gestational age; $C P B$, cardiopulmonary bypass; $X C$, aortic crossclamp time; $T$ min, lowest temperature on bypass; $I C U$, intensive care unit; $H L H S$, hypoplastic left heart syndrome; $M A$, mitral atresia; $A A$, aortic atresia; $I A S$, interatrial septum; $P A B$, pulmonary artery banding; $D O L$, day of life; $P O D$, postoperative day; $M S$, mitral stenosis; $A S$, aortic stenosis.

after stage 1. One patient each had these events on PODs 6, 7, and 8, whereas the fourth patient had it on POD 13. All 4 patients were extubated at the time of intermittent hemodynamically stable supraventricular tachycardia. Two of them were subsequently treated with propranolol, 1 was treated with digoxin, and 1 was treated with propranolol and digoxin. A fifth patient with a large coronary fistula had ventricular tachycardia 90 minutes after CPB that was cardioverted and treated with lidocaine. This patient subsequently developed junctional ectopic tachycardia on POD 4 while still on ECMO, which was treated with amiodarone.

ICU LOS. Two of the 5 patients who underwent IE had an uncomplicated course and ICU LOS of 2 and 3 days. Of the remaining 3 patients, the first (patient 5 in Table 4) had ICU LOS prolonged because of chylothorax and the need for chest tube drainage. The second (patient 7 in Tables 3 and 4) had feeding issues related to left vocal cord palsy that prolonged ICU LOS to 8 days. The third patient had a swallowing dysfunction, requiring reintubation for aspiration on POD 1 (patient 13 in Table 4). Although re-extubation was achieved the next day, ICU LOS was prolonged to 20 days.

Patients with ICU LOS more than the median 8 days had a higher incidence of surgical interventions, reintubations, and a higher need for nasogastric supplemental feeding on discharge when compared with those with shorter ICU LOS despite having comparable extubation times (Table 5).

The surgical interventions were as follows: One patient with open sternum at the end of procedure had subsequent sternal closure; 1 patient with a large coronary fistula required mediastinal exploration and ECMO support 90 minutes after termination of $\mathrm{CPB} ; 1$ patient needed exploratory sternotomy for bleeding; and 1 patient needed right thoracotomy to evacuate organized blood on POD 15.

Twelve patients required supplementation of their oral feeds via nasogastric tube/gastrostomy upon discharge, including the 4 patients who had IE. Those who required supplementation of oral feeding had longer ICU LOS (15 [8-20] vs 5 [3-6], $P=.01)$ and post-ICU hospital stay $(12.5$ [8-16] vs 7 [6-9], $P=.02)$ despite having comparable extubation times (1.4 [0-6] vs $1.5(0.5-3), P=.94)$. Two patients were diagnosed with left vocal cord palsy by microlaryngoscopy on workup for symptoms suggestive of aspiration. One of them had recovered fully at the time of discharge, and the other needed nasogastric tube feeding. One patient with left diaphragmatic palsy treated with diaphragmatic plication underwent IE successfully.

Weight for age $z$ score on discharge for the cohort was 0.89 (0.12-1.44). Of the 20 patients discharged home after 
Methods

Reintubation rate against the extubation timing

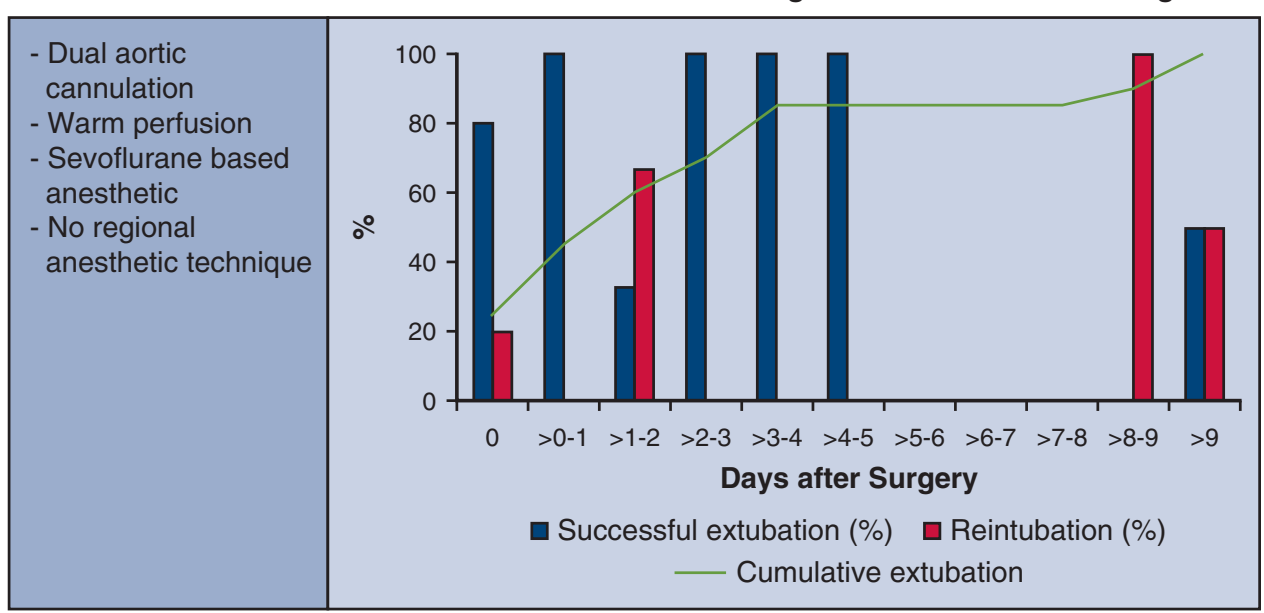

Immediate extubation in neonates undergoing Stage 1 Norwood did not increase the reintubation rate. $22 \%$ of the cohort was extubated in the operating room.

FIGURE 1. Graphical representation of the reintubation rate against the extubation timing.

Norwood 1, 1 had cardiac arrest at home on POD 33. Nineteen patients underwent bidirectional Glenn; there were 2 post-Glenn deaths and 2 heart transplants. Of the remaining 15 patients, 5 have undergone completion of Fontan. Patients were followed up for 825 (371-1473) days. The 1 -year survival was $74 \%$, and 3 -year survival was $60 \%$.

\section{DISCUSSION}

Our results demonstrate that the IE strategy can be extended to neonates undergoing complex cardiac surgical procedures such as stage 1 Norwood palliation. Although we found that patients undergoing IE after stage 1 Norwood did not have additional complications compared with those who were extubated subsequently, an extensive quantitative analysis of this small cohort was not possible. However, an analysis of complications and appraisal of our experience could be valuable.

The extubation time for the cohort was $1.3(0-3)$ days, ICU LOS was 8 (5-19) days, and postoperative hospital stay was 19 (12-30) days. Three of the 5 patients who had IE had ICU LOS that was longer than the

TABLE 5. Comparison of patients who had longer than median and shorter than median intensive care unit length of stay

\begin{tabular}{|c|c|c|c|}
\hline & Long ICU LOS $(n=10)$ & Short ICU LOS $(n=10)$ & $P$ value \\
\hline Age median (IQR) & $6(4-13)$ & $4(3.25-6.5)$ & .32 \\
\hline Gestational age median (IQR) & $39(38-39.5)$ & $39(39-39.3)$ & .59 \\
\hline Weight median (IQR) & $3.6(3.1-3.9)$ & $3.4(3.2-4.0)$ & .97 \\
\hline Preoperative intubation (yes-n) & 2 & 2 & 1 \\
\hline Gender (male-n) & 7 & 8 & 1 \\
\hline CPB median (IQR) & $105(98-138)$ & $97(89-104)$ & .17 \\
\hline $\mathrm{XC}$ median (IQR) & $26(24-43)$ & $28(23-32)$ & .88 \\
\hline $\mathrm{T}$ min median (IQR) & $32.3(32.1-32.8)$ & $33.4(32.1-34)$ & .32 \\
\hline Inotrope score median (IQR) & $9(5-10)$ & $5(5-5)$ & .09 \\
\hline Platelets mL/kg median (IQR) & $12(0-26)$ & $0(0-20)$ & .32 \\
\hline Last lactate in OR median (IQR) & $3(2-3.4)$ & $1.7(1.6-2.3)$ & .12 \\
\hline Extubation (d) median (IQR) & $1.5(0-8)$ & $1(0.25-3)$ & .57 \\
\hline Subsequent surgical interventions (n) & 4 & 0 & \\
\hline Reintubations (n) & 5 & 0 & \\
\hline Postoperative SVT (n) & 3 & 1 & .58 \\
\hline Oral feeds on discharge (n) & 1 & 7 & .02 \\
\hline
\end{tabular}

$\overline{I C U}$, Intensive care unit; $L O S$, length of stay; $I Q R$, interquartile range; $C P B$, cardiopulmonary bypass; $X C$, aortic crossclamp time; $T$ min, lowest temperature on bypass; $O R$, operating room; $S V T$, supraventricular tachycardia. 
median for the cohort. Although chylothorax was the reason in 1 patient, feeding difficulties prolonged the ICU LOS for the other 2 patients. Stage 1 Norwood is associated with higher incidence of postoperative feeding abnormalities than most other congenital cardiac surgical procedures.

Our previous work on neonates demonstrated that IE was associated with shorter ICU LOS and expenses. ${ }^{6,7}$ However, such decrease in ICU LOS was not observed in this cohort. Multiple factors other than extubation time could be influencing the ICU LOS in patients post-Norwood 1 . Patients with longer than median ICU LOS and shorter than median ICU LOS had comparable extubation times. However, the longer than median ICU LOS group had a higher incidence of subsequent surgical interventions and reintubations. This group also had a higher number of patients dependent on nasogastric tube feeds at the time of discharge. We think that a coordinated effort with attention to multiple different aspects of a patient's recovery along with better understanding of the disease process and the perioperative alterations will refine the process of IE and maximize its impact on the ICU LOS.

Patients who needed ventilator assistance on the day of surgery had a relatively complicated postoperative course. The primary pathophysiology that necessitated preoperative ventilator assistance including prematurity can lead to prolonged postoperative ventilator assistance. Positive pressure ventilation by itself can also increase postoperative morbidity. ${ }^{5}$

Two of the 4 patients who had preoperative atrial septal gradient greater than $8 \mathrm{~mm} \mathrm{Hg}$ had IE; ICU LOS for those who had IE was 2 and 18 days. Although interatrial septectomy with pulmonary artery banding has now been demonstrated to improve outcome in HLHS associated with restrictive interatrial septum, ${ }^{10}$ this was not strictly incorporated into our practice at the time, and the decision on the procedure was made on a case-by-case basis. It is noteworthy that there were no deaths in this group during the hospital stay, and IE could be accomplished, given the higher incidence of pulmonary lymphovascular abnormalities in infants with postnatal interatrial gradient greater than $8 \mathrm{~mm} \mathrm{Hg.}{ }^{11}$

Dual arterial cannulation of the innominate artery and descending aorta has been an integral part of CPB management for aortic arch procedures at our institution since 2009. The improvement in outcome with antegrade cerebral perfusion over deep hypothermic circulatory arrest could partly be due to an improved splanchnic and lower-extremity perfusion. ${ }^{10}$ Because of the variation in the presence of collaterals, a wide variation in abdominal perfusion while on antegrade cerebral perfusion has been noticed. We speculate that maintenance of lower-body perfusion through a separate distal aortic cannula would avoid relying on the collaterals that are highly variable.
This technique also enables maintaining a higher temperature on $\mathrm{CPB}$ during aortic arch repair and may have contributed to successful IE in this cohort of patients. Although the optimal temperature during CPB is unknown, higher temperatures provide better cerebral perfusion ${ }^{12}$ and outcome benefits. ${ }^{7,13}$ Conclusive evidence in favor of normothermic or mildly hypothermic CPB is lacking, and our experience has been that higher temperature while on $\mathrm{CPB}$ is associated with higher IE rates in neonates. ${ }^{7}$

Our experience in this cohort has been that no alteration in respiratory status was necessary to treat arrhythmias. The incidence of postoperative arrhythmias requiring medical intervention in our population was $22 \%$, with the reported incidence being $33 \%$ to $50 \%$ post-stage 1 palliation. ${ }^{14,15}$ Longer aortic crossclamp time, deep hypothermia, and circulatory arrest are factors associated with postoperative arrhythmias. ${ }^{16}$ Three of the 4 patients in our cohort who developed arrhythmia in the postoperative period had been extubated at the time of the arrhythmia and did not need reintubation for rhythm management, and the other 2 had been ventilated.

Contrary to the significant decline in weight for age $z$ score observed on discharge after Norwood $1,{ }^{17}$ our cohort had normal weight for age $z$ scores. Lesser inflammation related to limited reperfusion injury and early feeding due to lack of splanchnic ischemia and shorter ventilator assistance may have contributed to better weight for age $z$ score in the cohort.

\section{CONCLUSIONS}

IE strategy can be extended to neonates undergoing complex procedures including stage 1 Norwood palliation. A larger cohort may be able to delineate the determinants of IE and its outcome benefits after complex neonatal surgery.

\section{References}

1. Norwood WI, Lang P, Casteneda AR, Campbell DN. Experience with operations for hypoplastic left heart syndrome. J Thorac Cardiovasc Surg. 1981;82:511-9.

2. Tweddell JS, Hoffman GM, Fedderly RT, Berger S, Thomas JP Jr, Ghanayem NS, et al. Phenoxybenzamine improves systemic oxygen delivery after the Norwood procedure. Ann Thorac Surg. 1999;67:161-7.

3. Ohye RG, Schranz D, D'Udekem Y. Current therapy for hypoplastic left heart syndrome and related single ventricle lesions. Circulation. 2016;134:1265-79.

4. Gupta P, McDonald R, Gossett JM, Butt W, Shinkawa T, Imamura M, et al. Single-center experience of extubation failure in infants undergoing the Norwood operation. Ann Thorac Surg. 2012;94:1262-8.

5. Wellman TJ, Winkler T, Costa EL, Musch G, Harris RS, Zheng H, et al. Effect of local tidal lung strain on inflammation in normal and lipopolysaccharide-exposed sheep. Crit Care Med. 2014;42:e491-500.

6. Varghese J, Kutty S, Abdullah I, Hall S, Shostrom V, Hammel JM. Preoperative and intraoperative predictive factors of immediate extubation after neonatal cardiac surgery. Ann Thorac Surg. 2016;102:1588-95.

7. Varghese J, Kutty S, Bisselou Moukagna KS, Craft M, Abdullah I, Hammel JM. Five-year experience with immediate extubation after arterial switch operations for transposition of great arteries. Eur J Cardiothorac Surg. 2017;51:728-34.

8. Hammel JM, Deptula JJ, Siecke R, Abdullah I, Duncan KF. Descending aortic and innominate artery cannulation for aortic arch repair with mildly hypothermic continuous cardiopulmonary bypass 
in infants and children. World J Pediatr Congenit Heart Surg. 2013; 4:418-21.

9. Davis D, Davis S, Cotman K, Worley S, Londrico D, Kenny D, et al. Feeding difficulties and growth delay in children with hypoplastic left heart syndrome versus d-transposition of the great arteries. Pediatr Cardiol. 2008;29:328-33.

10. Algra SO, Schouten AN, van Oeveren W, van der Tweel I, Schoof PH, Jansen NJ, et al. Low-flow antegrade cerebral perfusion attenuates early renal and intestinal injury during neonatal aortic arch reconstruction. J Thorac Cardiovasc Surg. 2012;144:1323-8.

11. Saul D, Degenhardt K, Iyoob SD, Surrey LF, Johnson AM, Johnson MP, et al. Hypoplastic left heart syndrome and the nutmeg lung pattern in utero: a cause and effect relationship or prognostic indicator? Pediatr Radiol. 2016;46:483-9.

12. Jonassen AE, Quaegebeur JM, Young WL. Cerebral blood flow velocity in pediatric patients is reduced after cardiopulmonary bypass with profound hypothermia. J Thorac Cardiovasc Surg. 1995;110:934-43.

13. Tsai JY, Pan W, Lemaire SA, Pisklak P, Lee VV, Bracey AW, et al. Moderate hypothermia during aortic arch surgery is associated with reduced risk of early mortality. J Thorac Cardiovasc Surg. 2013;146:662-7.
14. McFerson MC, McCanta AC, Pan Z, Collins KK, Jaggers J, da Cruz EM, et al. Tachyarrhythmias after the Norwood procedure: relationship and effect of vasoactive agents. Pediatr Cardiol. 2014;35:668-75.

15. Gist KM, Schuchardt EL, Moroze MK, Kaufman J, Cruz Ed, Campbell DN, et al. Tachyarrhythmia following Norwood operation: a single-center experience. World J Pediatr Congenit Heart Surg. 2014;5:206-10.

16. Rekawek J, Kansy A, Miszczak-Knecht M, Manowska M, Bieganowska K, Brzezinska-Paszke M, et al. Risk factors for cardiac arrhythmias in children with congenital heart disease after surgical intervention in the early postoperative period. J Thorac Cardiovasc Surg. 2007;133:900-4.

17. Burch PT, Gerstenberger E, Ravishankar C, Hehir DA, Davies RR, Colan SD, et al; Pediatric Heart Network Investigators. Longitudinal assessment of growth in hypoplastic left heart syndrome: results from the single ventricle reconstruction trial. J Am Heart Assoc. 2014;3:e000079.

Key Words: hypoplastic left heart syndrome, Norwood operation, immediate extubation, outcomes

Readers who found these articles interesting may also like to read the following papers found in recent and future issues of our sister publications, Seminars in Thoracic and Cardiovascular Surgery and Operative Techniques in Thoracic and Cardiovascular Surgery!

\section{Congenital: Hypoplastic Left Heart Syndrome}

ORIGINAL SUBMISSION: Improved Outcomes in Management of Hypoplastic Left Heart Syndrome Associated with Congenital Diaphragmatic Hernia: an Algorithmic Approach. Kaitlin Balduf. Semin Thoracic Surg 2018: 191-196.

Editorial Commentary: Hypoplastic Left Heart Syndrome With a Hypoplastic Lung in Congenital Diaphragmatic Hernia: What Should Be Done First? Shu-Chien Huang. Semin Thoracic Surg 2018: 197-198. 